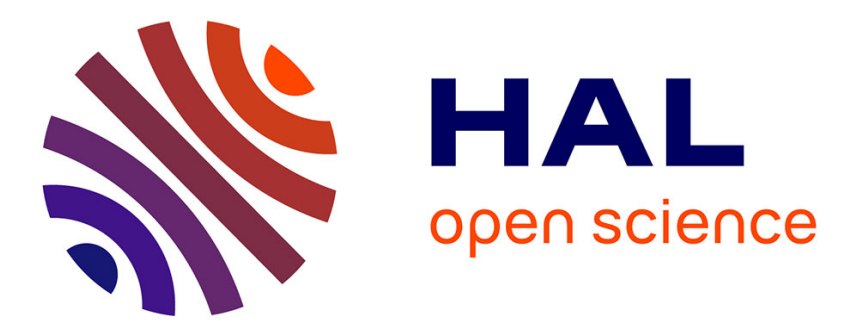

\title{
Determination of Site Specific Binding Environments of Surface Sorbed Cesium on Clay Minerals by Cs-EXAFS
}

\author{
K. Kemner, D. Hunter, P. Bertsch, J. Kirkland, W. Elam
}

\section{To cite this version:}

K. Kemner, D. Hunter, P. Bertsch, J. Kirkland, W. Elam. Determination of Site Specific Binding Environments of Surface Sorbed Cesium on Clay Minerals by Cs-EXAFS. Journal de Physique IV Proceedings, 1997, 7 (C2), pp.C2-777-C2-779. 10.1051/jp4:1997234 . jpa-00255313

\section{HAL Id: jpa-00255313 https://hal.science/jpa-00255313}

Submitted on 1 Jan 1997

HAL is a multi-disciplinary open access archive for the deposit and dissemination of scientific research documents, whether they are published or not. The documents may come from teaching and research institutions in France or abroad, or from public or private research centers.
L'archive ouverte pluridisciplinaire HAL, est destinée au dépôt et à la diffusion de documents scientifiques de niveau recherche, publiés ou non, émanant des établissements d'enseignement et de recherche français ou étrangers, des laboratoires publics ou privés. 


\title{
Determination of Site Specific Binding Environments of Surface Sorbed Cesium on Clay Minerals by Cs-EXAFS
}

\author{
K.M. Kemner ${ }^{*, 1}$, D.B. Hunter ${ }^{* *}$, P.M. Bertsch ${ }^{* *}$, J.P. Kirkland ${ }^{* * *}$ and W.T. Elam ${ }^{*}$ \\ *. Naval Research Laboratory, Code 6685, Washington, DC 20375, U.S.A. \\ ** Advanced Analytical Center for Environmental Sciences, University of Georgia/SREL, Aiken, SC, U.S.A. \\ *** SFA Inc., Landover, MD, U.S.A.
}

\begin{abstract}
Transport behavior of ${ }^{137} \mathrm{Cs}$ in the environment is regulated by surface sorption reactions on clay mineral surfaces. To provide greater understanding of Cs transport processes, XAFS investigations of the local environments of ${ }^{133} \mathrm{Cs}$ sorbed to clay minerals were conducted on $\mathrm{Cs}-\mathrm{Ca}$ exchanged clay suspensions at the Cs LIII-edge. With decreased surface loadings of $\mathrm{Cs}$, the $\mathrm{Cs}$ local environment exhibited increased long range order beyond $6 \AA$. Identification of $\mathrm{Cs}$ in expanded, semi-collapsed and collapsed interlayer environments was determined by correlating radial distances and Fourier transform peak amplitudes representing $\mathrm{Cs}-\mathrm{O}$ and $\mathrm{Cs}-\mathrm{AV} / \mathrm{Si}$ in the octahedral and tetrahedral layers. Despite the difficulties of analyzing XAFS data of adsorbed atoms in multiple environments, isolation of $\mathrm{Cs}$ in more specific sites by selective exchange should allow detailed analysis and identification of predominant binding environments of cations to clay surfaces.
\end{abstract}

\section{INTRODUCTION}

The ability to develop adequate models for predicting the fate of inorganic contaminants in both surface and subsurface environments is highly coupled to an accurate description of the partitioning of these constituents between the solid and solution phases and ultimately on the capability to provide specific molecular-level information on species distribution in both of these phases. A radionuclide contaminant of particular interest is ${ }^{137} \mathrm{Cs}$. To date, little work has been done to directly identify the nature of Cs binding sites in aquated clays in situ. X-ray absorption fine structure (XAFS) spectroscopy is well suited to probe $\mathrm{Cs}$ coordination environments in clays since it is capable of very detailed molecular structure determinations.

\section{PRELIMINARY STUDIES}

In previous investigations, we have used XAFS to investigate the average local environment of solution and solid phase complexes of Cs with Dibenzo-18-Crown-6 ether (Cs-D18C6) [1,2]. Results of the analysis of the Cs LIII edge data from the crown ether solutions identified the presence of ternary crown-ether-Cs-Br contact pairs. Results from the analysis of the Cs LIII edge XAFS measurements made on the dried Cs-D18C6 complexes showed that, upon evaporation, the Cs atom's local environment changes from a crown-ether complex to a predominantly crystalline $\mathrm{CsBr}$ environment separate from the crownether. This recrystallization during drying illustrates the importance of in situ methods for the chemical speciation of soluble complexes. A more in-depth discussion of the data acquisition and analysis used for all these experiments, the Cs LIII-edge results as well as the $\mathrm{Br} \mathrm{K}$-edge results is presented elsewhere [2].

\section{Cs SORPTION TO CLAYS}

A number of $\mathrm{Cs}$ exchanged and fractionally exchanged $\left(\mathrm{Cs}_{x} \mathrm{Ca} 100-x \mathrm{Cl}\right)$ phyllosilicate minerals including smectite (SWy-1), illite (Silver Hill) and phlogopite mica [3] (representing a trend of non-collapsed to completely collapsed interlayer clays) were examined. Fluorescence measurements were made on aquated suspensions loaded in polypropylene bags.

One likely site of $\mathrm{Cs}$ binding in 2:1 clay minerals is the ditrigonal cavity that arises from six comer sharing silica tetrahedra. This cavity consists of six pairs of lone pair electron orbitals emanating from the surrounding ring of oxygen atoms; analogous to the Crown ether system described earlier. The reactivity of the ditrigonal cavity is governed by the electronegative charge distribution in the phyllosilicate structure. Isomorphic substitution of $\mathrm{Al}^{3+}$ for $\mathrm{Si}^{4+}$ in the tetrahedral sheet and substitution of $\mathrm{Fe}^{2+}$ or $\mathrm{Mg}^{2+}$ for $\mathrm{Al}^{3+}$ in the octahedral sheet increases localized negative charge that in turn effects surface complexation behavior [4].

The resulting $\chi(k)^{*} k^{3}$ data for the smectite and illite $(x=10 \%)$ and mica samples are shown in Fig. 1 a-c. The Fourier transforms $\left(2.5 \AA^{-1}-9.0 \AA^{-1}\right)$ of the data representing the smectite and illite series are shown in Figs. $2 \mathrm{a}$ and $2 \mathrm{~b}$ respectively. The Fourier transforms of the $\chi(k)^{*} k^{3}$ data $\left(2.5 \AA^{-1}-9.0 \AA^{-1}\right)$ for the smectite and illite clay $(x=10 \%)$ and the mica are shown in Fig. 2c. Qualitative inspection of these data illustrates several trends. For the Cs-saturated clays $(x=100 \%)$, limited long range ordering can be deduced. However, at decreased $\mathrm{Cs}$ surface loadings, via exchange with $\mathrm{Ca}$ (Figs. $2 \mathrm{a}$ and $2 \mathrm{~b}$ ), the $\mathrm{Cs}$ local

\footnotetext{
${ }^{1}$ Présent address : Environmental Research Division, Argonne National Lab, Argonne, IL 60439, USA.
} 
environment exhibits increased long range order beyond $6 \AA$. Inspection of the Fourier transforms in Fig. 2c shows similar peak amplitudes for the mica and illite clay. This is consistent with the majority of the Cs ions residing within the collapsed layers of the illite clay. In Fig. 2c, the Fourier transform representing the smectite clay shows peak amplitudes approximately 3 to 4 times smaller than either the mica or the illite clay. In addition, the peak locations for the smectite sample are shifted to higher $r$-values. These trends are consistent with the $\mathrm{Cs}$ ions in the smectite being in a more disordered environment in expanded layers (i.e. the Cs ions being loosely associated with a single ditrigonal cavity at the clay surface). Another interesting trend in the Fourier peak amplitudes is seen for the smectite series near $2 \AA$ (Fig. 2b). Although all other peak amplitudes increase with decreasing $\mathrm{Cs} / \mathrm{Ca}$ concentration, the peak amplitudes near $2 \AA$ decrease with decreasing $\mathrm{Cs} / \mathrm{Ca}$ concentrations. This peak (when appropriately phase shifted) is located at an approximate Cs-O radial distance for hydrated Cs. This trend is consistent with the hypothesis that the more tightly bound Cs (most prominently seen when $x=10 \%$ ) are less hydrated than the loosely bound Cs (most prominently seen when $x=100 \%$ ). These qualitative results, however, do not eliminate the possibility of Cs sorption to the clay surface in places other than the ditrigonal cavity.

Future studies of these systems will include detailed FEFF6 simulations of the Cs ion local environments in these different sites. Then, a more detailed analysis may be done not only to identify the general sites, but to address the question of distortions of the different sites with the introduction of the Cs ion.

\section{Acknowledgments}

This research was performed while KMK held a National Research Council Fellowship and was also supported by Financial Assistance Award Number DE-FC09-96SR18546 from the U.S. Department of Energy to the University of Georgia Research Foundation.
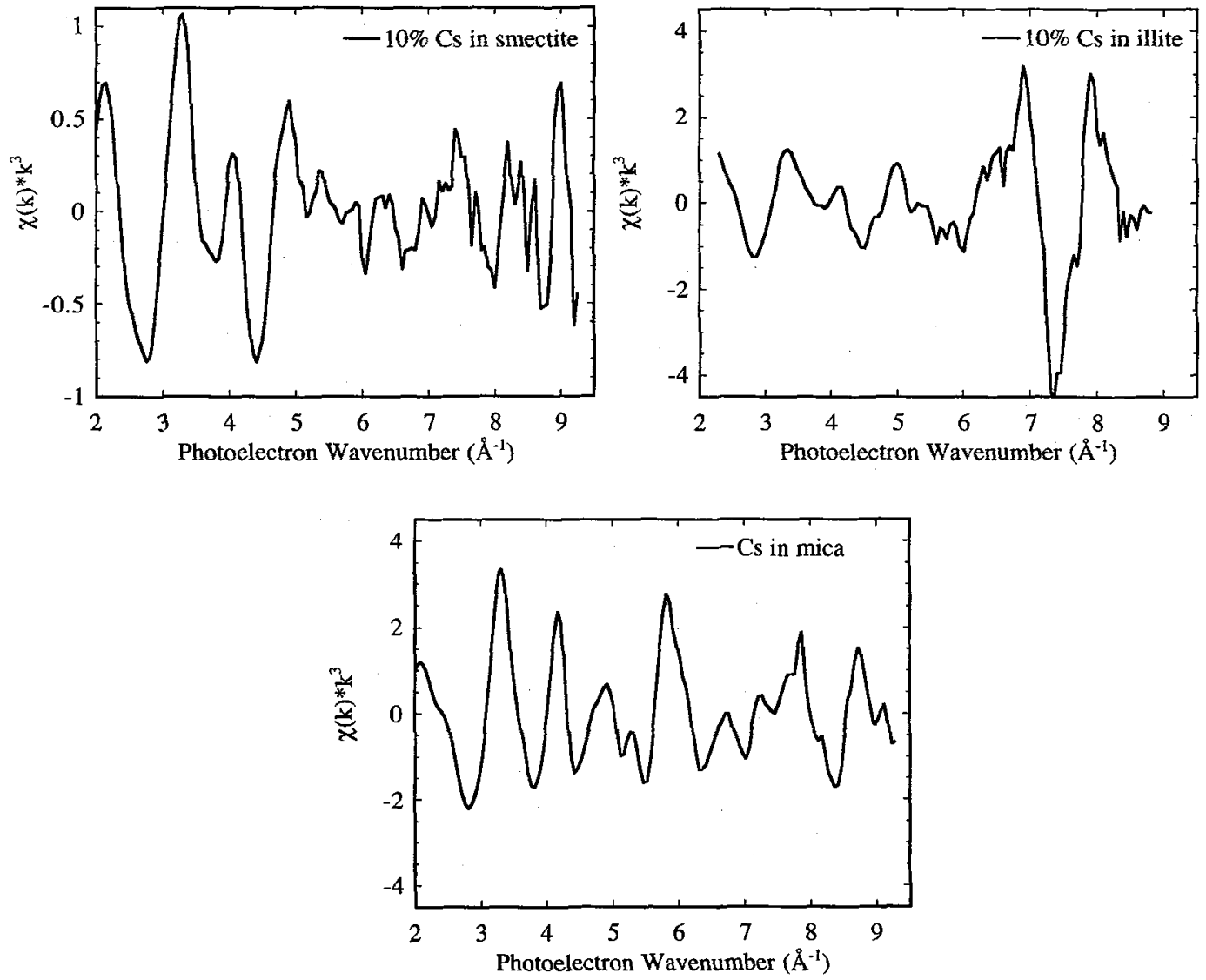

Figure 1: Six merged $\chi(k)^{*} k^{3}$ data sets representing the quality of data from a smectite (a), illite (b) anc 

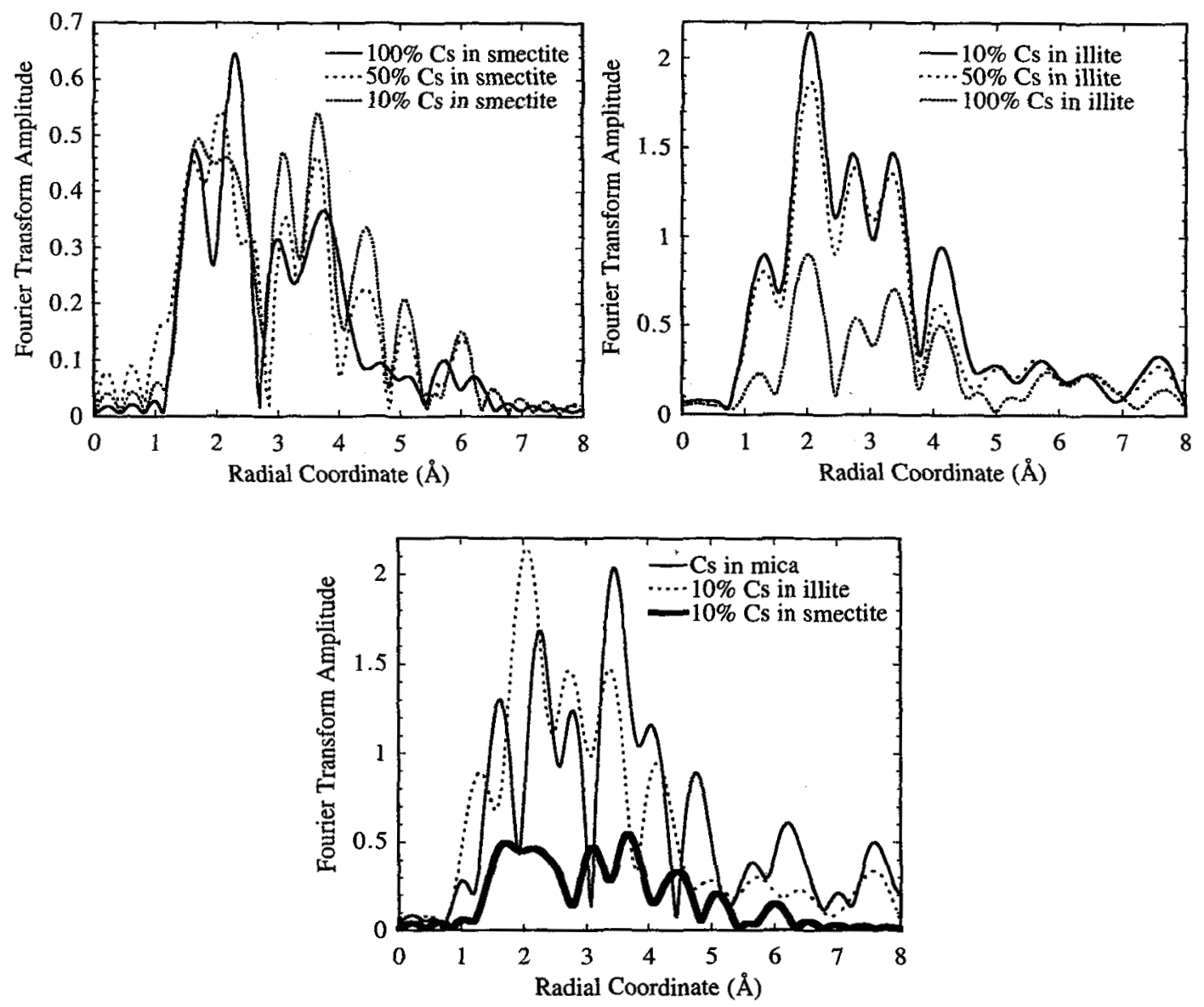

Figure 2: Fourier transforms of experimental Cs LIII edge $\chi(k) * k^{3}$ data depicting Cs incroduced to a smectite clay via $1 M$ $\mathrm{Cs}_{x} \mathrm{Ca}_{100-x} \mathrm{Cl}$ water solution where $\mathrm{x}=10 \%, 50 \%$, and $100 \%$. (a) Fourier transforms of data representing $\mathrm{Cs}$ introduced to an illite clay via $1 \mathrm{M} \mathrm{Cs} \mathrm{Ca}_{100-\mathrm{x}} \mathrm{Cl}$ water solution where $\mathrm{x}=10 \%, 50 \%$, and $100 \%$. (b) Fourier transforms of data representing $\mathrm{Cs}$ in a collapsed interlayer double-cage site (thin solid line), Cs introduced to illite clay via $1 \mathrm{M} \mathrm{Cs} 10 \mathrm{Ca} 90 \mathrm{Cl}$ water solution (dotted line), and $\mathrm{Cs}$ introduced to smectite clay via $1 \mathrm{M} \mathrm{Cs}_{10} \mathrm{Cag}_{90} \mathrm{Cl}$ solution (thick solid line). Note that the amplitude of $\mathrm{Cs}$ in mica is approximately twice as large as the amplitude of $\mathrm{Cs}$ in smectite, possibly indicating surface sorption to a single electronegative cage site.

\section{References}

[1] Kemner K. M., Elam W. T., Hunter D. B. and Bertsch P. M., Physica B 208 \& 209 (1995) 735-736.

[2] Kemner K. M., Hunter D. B., Elam W. T. and Bertsch P. M., J. Phys. Chem. 100 (1996) 11698-11703.

[3] Paulus W. J., Komarneni S. and Roy R., Nature 357 (1992) 571-573.

[4] Sposito G., The Surface Chemistry of Soils (Oxford University Press, NY, 1984). 